\title{
Erfaringer med intervensjonsforsøk i yrkesepidemiologi: Basert på studier av miljøtiltak for å forbedre inneklima i kontormiljø
}

\author{
Knut Skyberg og Knut Skulberg \\ Arbeidsmedisinsk seksjon, Statens arbeidsmiljøinstitutt
}

\begin{abstract}
SAMMENDRAG
Basert på to intervensjonsforsøk rettet mot helseeffekter i hud og øvre luftveier før og etter inneklimatiltak, drøftes erfaringer med design, metoder og analyse av data. Intervensjonene som ble prøvet ut var antistatisk behandling av dataskjerm $(n=117)$ og storrengjøring i kontormiljø $(n=104)$. Det ble målt støvkonsentrasjon under vanlig arbeid med direktevisende partikkelteller. Ved støvkonsentrasjoner $>50$ $\mu \mathrm{g} / \mathrm{m}^{3}$ hadde tiltakene effekt. Antistatisk behandling av skjermen førte til reduserte hudplager i ansiktet. Kolorimetrisk måling av rødfarge i ansiktet viste ingen forskjeller mellom intervensjon og placebo. Rengjøring av enkeltkontorer førte til reduserte slimhinneplager i øvre luftveier. Personer med tendens til redusert nesepassasje viste økning av hulmål-parametre, målt med akustisk rhinometri. I begge forsøk ble endring i helsevariabler før-etter i intervensjonsgruppen sammenlignet med endring i kontrollgruppen. Det konkluderes med at intervensjon som metode i arbeidsmedisinsk forskning er ressurskrevende, men har en rekke fordeler som metoden deler med klinisk kontrollerte forsøk.
\end{abstract}

\section{Skyberg K, Skulberg K. Experiences from intervention trials in occupational epidemiology, based on studies of measures to improve indoor air in offices. Nor J Epidemiol 1999; 9 (1): 71-77.}

\section{ENGLISH SUMMARY}

Based on two intervention trials on health effects in skin and upper airways, before and after indoor air quality measures, experience with design, methods and data analysis are discussed. Applied interventions were antistatic treatment of VDU $(n=117)$ and comprehensive cleaning of the office $(n=104)$. Dust concentrations during usual work were measured, using a particle counter. The interventions showed effect when the dust concentration was $>50 \mu \mathrm{g} / \mathrm{m}^{3}$. Antistatic treatment of the VDU lead to reduced facial skin symptoms. Colorimetric measurements, however, showed no differences between the intervention and control groups. Cleaning of single offices lead to a reduction of mucosal complaints in the upper airways. Persons with a tendency to reduced nasal passage showed an increase in nasal volume parameters, measured by acoustic rhinometry. In both trials the differences in health indicators before and after in the intervention group were compared to differences in the control group. It is concluded that intervention methods used in occupational health research are resource demanding, but have a number of advantages that this method shares with controlled clinical trials.

\section{INNLEDNING}

Intervensjonsforsøk, som er en felt-eksperimentell metode, er en type studier der kravene til det klassiske kontrollerte eksperiment forsøkes oppfylt. Når betingelsene i tilstrekkelig grad er oppfylt, gir metoden svar på om innføringen av eller endringen av en eksponering har helsemessig betydning. Til forskjell fra laboratorieeksperimentet skjer forsøket i det virkelige liv, $\mathrm{i}$ et naturlig samspill med andre faktorer i miljøet. Dette øker generaliserbarheten av eventuelle funn. Fordi studien er prospektiv, vil datakvaliteten kunne bli høy, og eventuelle modifiserende og konfunderende faktorer kan måles.

Intervensjonsforsøk er ofte tradisjonelt lite omtalt i lærebøker i epidemiologi. Derimot er slike metoder mer utfyllende beskrevet i samfunnsvitenskapelige lærebøker, både generelle (Reaves, 1992) og i pedagogikk (Cook \& Campbell, 1979). Men i de senere år har inneklimarelaterte helseplager (Jaakkola et al, 1991) og muskel-skjelettplager (Aarås et al, 1998) vært to områder der intervensjonsmetoden oftere har blitt benyttet i arbeidsmiljøforskning.

En skulle tro at forholdene ligger godt til rette for å 
gjennomføre intervensjonsstudier i arbeidslivet. I bedriftene har man populasjoner som det er mulig å ha god kontroll over. Mange tiltak gjennomføres for å forbedre arbeidsmiljøet uansett, så hvorfor ikke iverksette et tiltak på en vitenskapelig holdbar måte? Det er den eneste sikre måte å evaluere om tiltaket virket etter hensikten. Årsakene til at intervensjonsundersøkelser fortsatt benyttes forholdsvis sjelden, må antas å være en blanding av praktiske og teoretiske problemer. Noen av disse kan overkommes, forutsatt at planleggingen av studien er god.

\section{MATERIALE}

\section{Eksempel I - elektriske felt fra dataskjerm og hudplager}

I det første intervensjonsprosjektet så vi på sammenhengen mellom statisk elektriske felt, støv og hudplager i ansiktet hos dataskjermbrukere (Skulberg et al, 1996). Sammenhengen mellom inneklima og hudplager er tidligere studert spesielt i Sverige (Stenberg, 1994). Etter en spørreskjemaundersøkelse om inneklima og helseforhold, med vel 4500 personer som returnerte skjemaet, rekrutterte vi dataskjermbrukere med hudplager fra fire større bedrifter til et intervensjonsforsøk. Deltakerne skulle ha en høy forekomst av hudplager, i henhold til antall og alvorlighetsgrad av symptomer registrert med spørreskjemaet. Det ble benyttet en symptomindeks med skala $0-8$ basert på 4 spørsmål og svaralternativer $0-2$. For å delta skulle personene ha minimum 4 symptompoeng. Videre skulle de arbeide minst 4 timer foran skjermen daglig. Ut fra kriteriene var det 279 personer som var aktuelle for inklusjon. Blant dem ble trukket 120 personer tilfeldig. De 120 ble forespurt, og supplert ved videre trekning, inntil vi hadde 120 deltakere som var villig til å delta og ikke hadde planlagt fravær lengre enn 3 dager $\mathrm{i}$ intervensjonsperioden. Halvparten ble fordelt til en intervensjonsgruppe, som fikk redusert statisk elektriske felt fra dataskjermen, og halvparten til en kontrollgruppe som fikk placebo-tiltak (tiltak som så likt ut, men ikke forandret det elektriske feltet). Fordeling til intervensjon eller kontroll ble gjort slik at alder, kjønn og allergistatus var lik, av en forsker som ikke deltok i den videre datainnsamlingen eller analysen. 117 personer fullførte forsøket.

Før tiltaket, etter 2 uker og etter 4 uker ble det registrert symptomer med spørreskjema, rødfarge i huden ble målt med colorimeter, og konsentrasjon/ reaksjonstid ble målt med fire databaserte tester. Statiske og lavfrekvente elektriske felt rundt skjermen og støv i luften ble målt før og etter tiltaket. Støvmålinger ble gjort nær skjermen, under vanlig arbeid, med direktevisende partikkelteller. Personbårne heldagsmålinger av støv med filter og pumpe ble dessverre mislykket.

\section{Eksempel II - rengjoring og slimhinneplager}

I det neste intervensjonsprosjektet så vi på betydningen av å redusere støvmengden i lufta ved storrengjøring i et kontorbygg (Skulberg et al, 1999). Helseeffektparametrene her var slimhinneplager, rødfarge $i$ ansiktshuden og nesepassasje. Slimhinneplager ble registrert med tilsvarende spørreskjema som i første forsøk, hudfargen ble målt med colorimeter, og nesepassasje målt med akustisk rhinometri. Målinger av nesepassasje med akustisk rhinometri er tidligere benyttet i en tverrsnittsundersøkelse av inneklima på skoler (Wålinder et al, 1997). Blant de 967 personene ansatt i én bedrift, som returnerte et spørreskjema om inneklimaplager, ble de 120 med mest plager som også var ikke-røykere invitert til å delta. Etter et frafall på 2 personer, ble 118 kontoransatte fordelt til en intervensjonsgruppe og en kontrollgruppe. 14 personer falt fra $\mathrm{i}$ undersøkelsesperioden. De 49 personene som fullførte studien i intervensjonsgruppen fikk en omfattende storrengjøring, også himlinger i kontoret ble rengjort. Teppegulv, stolputer og gardiner ble støvsuget. Permer ble tatt ut av reolene, og støvsuget en og en. På denne måten ble mengden svevestøv i lufta senket med $28 \%$ i rom med $>50 \square \mathrm{g} / \mathrm{m}^{3}$ støv på forhånd. I kontrollgruppen på 55 personer ble bare lett tilgjengelige flater vasket.

\section{RESULTATER}

\section{Eksempel I - elektriske felt fra dataskjerm og hudplager}

Vi fant at når det var mer enn $50 \square \mathrm{g} / \mathrm{m}^{3}$ støv i luften, ble hudplagene redusert $\mathrm{i}$ den gruppen som fikk redusert det elektriske feltet. Det var stor spredning i støvkonsentrasjonene, medianene for de fire bedriftene varierte fra 24 til $74 \square \mathrm{g} / \mathrm{m}^{3}$. Støvfraksjonen over 10 $\square \mathrm{g} / \mathrm{m}^{3}$ dominerte. Rødfargen i huden falt tydelig fra før til etter intervensjonen, men det var ingen statistisk signifikant forskjell mellom intervensjons- og kontrollgruppen. De databaserte testene viste forbedring fra før til etter-situasjon, men heller ikke her var det tydelig forskjell mellom intervensjon og kontroll. Multivariat analyse av hvilke faktorer som forbedret hudplagene mest, viste at graden av hudsymptomer før intervensjon hadde størst forklart varians, deretter kom endring av elektrisk felt og kjønn (menn bedre effekt enn kvinner).

\section{Eksempel II - rengjoring og slimhinneplager}

De som fikk sitt kontor grundig storrengjort rapporterte reduksjon av irritasjonsplager i slimhinnene. Nesevolumet målt med akustisk rhinometri økte med $15 \%$ i intervensjonsgruppen. Multivariat analyse viste at både for irritasjonsplager og nesevolum var førnivå viktigste uavhengige variabel, dernest kom intervensjon/kontroll, fulgt av allergistatus. 
Tabell 1. Symptomindeks for hudplager før og etter tiltak (medianer for skåringstall før og etter intervensjon/placebo, samt 25-, 50- og 75- percentiler for endring). Eksempel I.

\begin{tabular}{|c|c|c|c|c|c|c|c|c|c|c|}
\hline & \multicolumn{5}{|c|}{ Placebo-gruppe } & \multicolumn{5}{|c|}{ Intervensjonsgruppe } \\
\hline & \multirow[b]{2}{*}{ Før } & \multirow[b]{2}{*}{ Etter } & \multicolumn{3}{|c|}{ Endring } & \multirow[b]{2}{*}{ Før } & \multirow[b]{2}{*}{ Etter } & \multicolumn{3}{|c|}{ Endring } \\
\hline & & & 25 & 50 & 75 & & & 25 & 50 & 75 \\
\hline Alle $(\mathrm{N}=117)$ & 4,0 & 4,0 & $-1,0$ & 0,0 & 0,5 & 4,0 & 3,5 & $-1,5$ & $-1,0 *$ & 0 \\
\hline Lite støv $(\mathrm{N}=44)$ & 4,5 & 4,0 & $-2,0$ & $-0,5$ & 0,5 & 4,0 & 4,0 & $-1,0$ & $-1,0$ & 0,5 \\
\hline Mye støv $(\mathrm{N}=43)$ & 4,0 & 4,0 & $-1,0$ & 0,0 & 0,5 & 4,0 & 3,0 & $-2,0$ & $-1,5^{*}$ & $-0,5$ \\
\hline
\end{tabular}

*Statistisk signifikant forskjell mellom endring for intervensjonsgruppen vs. kontrollgruppen, MannWhitney U test, to-sidig, signifikansnivå $\mathrm{p}=0,05$. Støvmålinger fantes bare for 87 deltakere.

Tabell 2. Symptomindeks før og endring etter tiltak (aritmetisk gjennomsnitt). Eksempel II.

\begin{tabular}{|c|c|c|c|c|c|c|c|}
\hline \multirow[b]{2}{*}{ Plager } & \multirow[b]{2}{*}{ Skala } & \multicolumn{3}{|c|}{ Kontroll } & \multicolumn{3}{|c|}{ Intervensjon } \\
\hline & & $\mathrm{N}$ & Førverdi & Endring $^{\mathrm{a}}$ & $\mathrm{N}$ & Førverdi & Endring $^{\mathrm{a}}$ \\
\hline Generelle & $0-10$ & 49 & 3,1 & $-0,2$ & 45 & 3,7 & $-0,6$ \\
\hline Irritasjon & $0-8$ & 55 & 3,5 & $-0,1$ & 49 & 3,6 & $-0,8^{*}$ \\
\hline Hud & $0-8$ & 53 & 2,2 & $-0,4$ & 48 & 2,3 & $-0,2$ \\
\hline
\end{tabular}

* $\mathrm{p}<0,01$ T-test: Forskjell i endring mellom intervensjons- og kontrollgruppen.

Øvrige forskjeller: $p$-verdi $>0,05$

a Positive tall betyr økning, negative tall betyr reduksjon etter intervensjon

Tabell 3. Nesepassasje før, og endring etter tiltak (gjennomsnittlige skåringstall). Eksempel II.

\begin{tabular}{lccccccc}
\hline & \multicolumn{3}{c}{ Kontroll } & & \multicolumn{3}{c}{ Intervensjon $^{n}$} \\
\cline { 2 - 4 } \cline { 6 - 7 } & $\mathrm{N}$ & Førverdi & Endring $^{\mathrm{a}}$ & & $\mathrm{N}$ & Førverdi & Endring $^{\mathrm{a}}$ \\
\hline MCA2 $^{\mathrm{b}}$ & 55 & 1,09 & $-0,02$ & & 49 & 1,02 & $0,05^{*}$ \\
VOL2 $^{\mathrm{b}}$ & 55 & 7,40 & $-0,53$ & & 49 & 6,54 & $0,62^{*}$ \\
\hline
\end{tabular}

* $\mathrm{p}<0,01$ T-test: Forskjell i endring mellom kontroll og intervensjonsgruppen.

a Positive tall betyr økning, negative tall betyr reduksjon etter intervensjon

b MCA2 angir areal $\mathrm{i} \mathrm{cm}^{2}$, og VOL2 volum $\mathrm{i} \mathrm{cm}^{3}$.

\section{DISKUSJON}

\section{Erfaringer med intervensjon som metode $i$ årsaksforskning}

\section{Når kan intervensjon benyttes?}

Intervensjonsforsøk i arbeidslivet må etisk sett utføres slik at man forventer en helsefremmende effekt. I intervensjonsforsøk II kunne vi teoretisk tilføre økt mengde svevestøv i kontoret for å studere om økt støvmengde ga økte irritasjonsplager. Et slikt forsøk ville være etisk tvilsomt. Vårt tiltak var å redusere støvmengden i kontoret og se på om dette førte til mindre irritasjonsplager. Ved at forsøket ble utført på denne måten «mistet» vi en del deltagere som hadde «lite» støv i sine kontorer før rengjøringen. Hvis en skal utføre forsøk hvor en forventer en helseskadelig effekt av tiltaket, må dette foregå i fullstendig kontrollerte former og med full sikkerhet om reversibilitet av helseeffekten. Dette vil av sikkerhetsgrunner måtte utføres som laboratorieforsøk.

\section{Reversibitet}

Når hypotesen om en relasjon mellom en eksponering og en helseffekt er formulert, blir det første spørsmålet, om denne kan studeres i et intervensjonsforsøk. 
Hvis forsøket skal være noenlunde avgrenset i tid og antall deltakere, vil krav til reversibilitet for helseeffekten ofte foreligge, men det finnes alternativer. Ett alternativ er å la studien omfatte nyansatte som ikke tidligere har vært utsatt for den miljøfaktoren som skal studeres. Kravet til reversibilitet er absolutt hvis man velger å intervenere på personer med allerede oppståtte helseplager.

Helseeffekten som skal måles må være reversibel i løpet av den tiden intervensjonen varer. Et eksempel er at hvis hudplagen som en observerer hos dataskjermbrukere var et kronisk ansiktseksem som ikke kunne forventes å endre seg på måneder, ville vi ikke kunne ha utført intervensjonsforsøk I, med etterundersøkelser etter to og fire uker. Slimhinneirritasjon fra øvre luftveier på grunn av dårlig inneklima (som i eksempel II) kan forventes å bli bedre i løpet av relativ kort tid ved innføring av et velegnet miljøtiltak. Et eksempel fra litteraturen på et intervensjonstudie med en enkel, klar hypotese, er en studie hvor husstøvmidd ble fjernet fra kontorstoler med kulde (Raw et al, 1993).

\section{Eksponeringsendring}

Det neste kravet til en intervensjonsstudie er at endringen i eksponering er stor nok og stabil nok til at man kan forvente en helseforbedring. Eksponeringsendringen bør måles i før- og etter-situasjon, og dersom målingene utføres for hver enkelt person, kan endringen også benyttes som variabel i en multivariat modell for mer detaljert analyse av sammenheng mellom forklarings- og effektvariable.

Grad av eksponeringsendring må velges. I intervensjonstudie I var tiltaket at de statiske elektriske feltene fra alle sider av dataskjermen ble fjernet, tastatur ble jordet, og en antistatmatte plassert under stolen. Disse tiltakene førte til reduserte felt fra skjermen og redusert oppladning av personen. Fra dataanalysen kunne en ikke si noe sikkert om hvilken av disse effektene som hadde størst betydning. Ideelt skulle en i intervensjonstudiet hatt flere undergrupper med ulik intervensjon (som ved fraksjonelt faktorielt design), en gruppe hvor bare elektriske felt fra skjermen ble redusert, en gruppe hvor bare personoppladningen ble redusert og en gruppe hvor både felt fra skjerm og personoppladning ble redusert. Et slikt forsøk ville krevd langt mer ressurser enn det vi hadde tilgjengelig. Vi valgte derfor i den første intervensjonsstudien å ha én større intervensjonsgruppe, hvor både felt fra skjerm og personoppladning ble redusert. I ettertid har det blitt utført en hovedoppgave ved Fysisk institutt, Universitetet i Oslo, hvor en har sett på størrelse av personoppladning (Martinsen, 1998) og sammenlignet dette med størrelse av de statisk elektriske feltene fra skjermen. Det ble funnet at personoppladningen er så lav at feltene fra skjermen vil dominere i de fleste tilfeller.

I det andre intervensjonsstudiet hadde vi også et lignende valg. Tiltaket var støvsanering på kontorer og vi valgte å ha en intervensjonsgruppe hvor en vasket ned kontoret og fjernet mineralull fra himlinger samtidig. Alternativt kunne vi konstruert tre eller fire undergrupper med forskjellig eksponeringsendringer. Til støtte for vårt valg kan vi vise til Kildesø og Schneider (1996) som utførte intervensjonsforsøk med forskjellige typer rengjøring og konkluderte blant annet med at selve rengjøringen måtte være mer intensiv enn det de hadde hatt i sitt intervensjonsforsøk. Oftedal et al (1995) utførte en intervensjonstudie på dataskjerm hvor tiltaket (skjermfilter) førte til en eksponeringsendring $\mathrm{i}$ form av redusert elektrisk felt, men denne eksponeringsendringen forekom i både kontroll- og intervensjonsgruppe.

En kan tenke seg ønskeligheten av å gjennomføre et intervensjonsforsøk over lang tid, f.eks. flere måneder eller et år. Dette vil teoretisk kunne føre til en undersøkelse om miljøtiltaket hadde ført til en «varig» helseeffekt. Men et krav til en intervensjonsstudie er at en utfører bare én eller et sett av kontrollerte endringer av eksponeringen. I praksis kan det skje mye i en bedrift, selv i løpet av en så kort tid som 4 uker. Både under første og annen intervensjon var dette et problem. Under den første var det $\mathrm{i}$ en av bedriftene planlagt full renovering av ventilasjonskanaler, i det andre prosjektet var det planlagt ombygninger av lokalene og flytting av arbeidsplasser. Vi klarte å få utsatt renoveringen av ventilasjonskanalene og i stor grad klarte vi å få inkludert deltagere som ikke flyttet kontorer. Dette viser at det er svært viktig å ha god løpende kontakt med personalavdeling, teknisk avdeling og renholdsavdeling i en bedrift under en intervensjonsundersøkelse på inneklima.

I intervensjonsforsøk på inneklima vil også årstid kunne ha betydning. Inneklimaplager er mer uttalt om vinteren og avtar utover våren og sommeren. Dette kan skyldes endrede eksponeringsforhold på grunn av ytre klima. I tillegg har en «problemet» med at våren er en «allergisesong» da bjørkeallergikere vil kunne få større endring i helseplager på grunn av allergien enn det en kan forvente av endringen i et miljøtiltak. For å unngå confounding på grunn av årstidsvariablen utførte vi intervensjons- og placebo tiltak samtidig, og helseundersøkelsene på intervensjonsgruppe og kontrollgruppe ble gjort til samme tid.

\section{Design}

\section{Inklusjon}

Når undersøkelsesgruppe skal defineres, vil det ofte være et valg mellom sensitivitet og generaliserbarhet. I begge våre forsøk inkluderte vi personer med symptomer. Dette øker sjansen for å finne effekt av tiltaket. For å holde ressursbruken nede vil en ofte ha minst mulig deltakergruppe, dog slik at det ikke gir for stor statistisk usikkerhet. Det viste seg imidlertid at korrelasjonen mellom subjektive symptomer og objektive 
helseeffektparametre var svak, både for hud- og slimhinneplager. I det andre forsøket krevet vi at deltakerne skulle være ikke-røykere. Hensiktene var å ikke ødelegge for eksponeringsmålingene, da røyking produserer så mye partikler, at tiltaket ikke kunne forventes å redusere partikkelnivået i luft. Dog vil eksklusjon av røykere umuliggjøre å studere en eventuell samvirkning mellom tobakksrøyk og andre inneklimafaktorer. Et annet forhold vi derimot prioriterte, var at deltakerne skulle være mest mulig til stede på sitt kontor, siden tiltakene skulle gjennomføres på den enkeltes kontor. I praksis viste det seg at deltakerne $\mathrm{i}$ forsøk II var ca. $40 \%$ av tiden utenfor kontoret, noe som gjør at en kan forvente en dårligere effekt av intervensjonen, enn om deltakerne hadde vært på kontoret hele arbeidsdagen.

Et annet problem når inklusjonskriterier skal fastsettes, kan være at disse varierer over tid, uavhengig av den eksponering som studeres. Hvis det går for lang tid mellom når symptomer som legges til grunn for inklusjon registreres og forsøket starter, kan personen bli symptomfri i mellomtiden. Dette problemet hadde vi særlig i det første forsøket.

\section{Kontrollgruppe}

På grunn av stor fare for placebo-effekt av arbeidsmiljøtiltak, er det viktig å ha kontrollgruppe. Ideelt bør kontrollgruppen oppstå ved enten fullstendig randomisert fordeling, eller ved en modifisert fremgangsmåte, der en sikrer at enkelte bakgrunnsvariabler fordeler seg likt i de to gruppene. I vårt første forsøk tok vi hensyn til kjønn, alder og allergi. I det neste forsøket sørget vi i tillegg for at alvorlighetsgraden av symptomer ble lik i de to gruppene, ut fra vår erfaring i det første forsøket, der ved tilfeldighet intervensjonsgruppen hadde mer rødhet $i$ ansiktet før tiltaket enn kontrollgruppen.

For å unngå at placebo-effekten bare oppstår i intervensjonsgruppen, er det ønskelig med blinding av tiltaket. Både deltakere og undersøkere bør være blindet $\mathrm{i}$ forhold til gruppe, i hele intervensjonsperioden. Et alternativ til blinding, som vi benyttet i eksempel I, er å benytte ulike varianter av et tiltak. Deltakerne $i$ kontrollgruppen vet da ikke at den varianten de opplever, i virkeligheten er et kontroll-tiltak. Denne design-varianten benyttet vi i eksempel II. Noe som taler for at kontrollgruppen heller bør defineres som en gruppe som får «alternativt tiltak» og informeres om det, kan være at de vil samarbeide bedre under forsøket.

Blinding av tiltaket kan være umulig, og dette vil særlig gi problemer i forhold til rapportering av subjektive symptomer. Men faktisk kan man i noen tilfeller tenke seg at manglende blinding av tiltaket kan føre til forstyrrelser i objektive helseeffektparametre. Dette kan inntreffe når helseeffekten som måles kan tenkes å være følsom for psykiske påvirkninger.

\section{Confounding}

Et annet problem i forholdet mellom intervensjons- og kontrollgruppe, kan være endring av en eksponeringsfaktor annen enn intervensjonen, som oppstår samtidig og rammer intervensjonsgruppen og kontrollgruppen ulikt. Dette kan i inneklimaforskning skje hvis intervensjonsgruppen er i én bygning eller i én fløy, mens kontrollgruppen er i en annen. I begge våre forsøk løste vi dette ved at tiltaket ble utført i hvert enkelt kontor, og at deltakerne i både intervensjons- og kontrollgruppen var spredd rundt om hverandre.

Det kan i utgangspunktet være vanskelig å skille fra hverandre hva som var mest vesentlig, hvis et tiltak består av flere elementer. Fra eksempel I kan nevnes at alle i intervensjonsgruppen fikk både antistatbehandling av skjermen og antistatmatte under stolen. Hva er da viktigst? Noe hjelp kan fåes fra eksponeringsmålingene og multivariatanalysen.

\section{Objektive helseeffektparametre}

Selv om endringer i subjektive symptomer kan være viktig nok for helsen, og placebo-effekten kan ivaretas ved kontrollgruppe og dobbel-blind-design, vil vi oftest være interessert $\mathrm{i}$ å registrere endringer i objektive helseeffektindikatorer (Gyntelberg et al, 1994). Dette fordi vi da får mer kunnskap om mekanismer for skadelig helseeffekt. I neste omgang kan kunnskap om relevante indikatorer benyttes $\mathrm{i}$ årsakssøking eller effektevaluering i praksis.

Objektive helseparametre ble, for å unngå påvirkning fra fysisk belastning og annen inneklimaeksponering under forflytning, målt i deltagernes egne kontorer i intervensjon II. Dette tilsier at måleutstyret må være mobilt, enkelt i bruk samt vise «objektive» mål. Akustisk rhinometri som ble benyttet, oppfyller disse kravene (Djupesland, 1998; Fischer et al, 1993; Mayhew \& O’Flynn, 1993).

\section{Objektive eksponeringsparametre}

I begge intervensjonstudiene ble svevestøv i luften målt med en optisk partikkelteller. Resultatene av disse målingene gis som støvkonsentrasjon i fraksjoner og total støvmengde. Det vil si at vi målte kvantitativ støvmengde. En erfaring var at det er vesentlig å standardisere aktiviteten i rommet under eksponeringsmåling (Miscallef et al, 1998). I det andre intervensjonsforsøket hvor rengjøring ble brukt som et støvsanerende tiltak måtte vi forvente at grundig rengjøring ville påvirke både kvantitativ støvmengde og innholdet i svevestøvet (Franke et al, 1997; Kemp et al, 1998). Valget av hvor mange eksponeringsmålinger som utføres vil avhenge av økonomi, mulige analyser og kunnskapsnivå.

Tiltaket må kunne evalueres med et objektivt eksponeringsmål. Vi har brukt måling av svevestøv- 
konsentrasjon i begge forsøkene og elektriske felt i det første. En mulig intervensjonstudie som ble vurdert av oss var å intervenere på ionemengde i luften. Dette har tidligere blitt rapportert å påvirke graden av inneklimasymptomer (Wyon, 1992). Imidlertid er ionemengde i luft svært vanskelig å måle og et slikt forsøk ble vurdert som umulig på grunn av manglende objektiv målemetode.

\section{Dataanalyse}

Først vil det være vanlig å se på eksponerings- og effektparametrene i en enkel gruppesammenligning. Hvor stor var endringen for eksponeringsfaktoren som skulle påvirkes? Er modifiserende eller confounding variabler også målt, kan disse også først rapporteres gruppevis. Videre sammenlignes differansen $i$ helseeffekt mellom etter- og før-situasjon for intervensjonsog kontrollgruppen. Denne analysemåten vil kontrollere for eventuell placeboeeffekt.

Multivariat analyse ble benyttet i begge intervensjonsforsøkene. I disse analysene ble confoundere lagt inn i modellen, og det ble foretatt analyse av «eksponeringmål» på forskjellige nivåer. Først ble gruppetilhørigheten lagt inn som et eksponeringsmål. Senere ble de direkte målte eksponeringsmålene lagt inn og gruppetilhørigheten ble tatt ut. I det andre intervensjonsstudiet ble det funnet at gruppetilhørigheten var en statistisk sikker forklaringsvariabel, mens endring $i$ mengde svevestøv ikke hadde noen sikker statistisk betydning. Dette kan tolkes som at rengjøringen hadde en effekt på irritasjonsplager, men at det ikke er den kvantitative støvmengden som har betydning men kanskje heller endringen i innholdet av svevestøvet.

Multivariat analyse viste også den relative betydningen av de statistisk sikre variablene $i$ forhold til hverandre.

En annen tilnærming under analysen kan være å se på substrata, der en skiller ut fra nivået på en mistenkt modifiserende faktor. I begge våre forsøk hadde vi nytte av å analysere separat den undergruppen av materialet som var karakterisert ved høyt støvnivå i kontoret. Dette var rimelig ut fra en forestilling om mekanismen for effekt.

Det var i det første forsøket en underhypotese at støv kunne vandre mot ansiktet $\mathrm{i}$ et elektrisk felt mellom dataskjerm og person, og at støv deponert på ansiktet ville gi hudplager. Ut fra dette kunne en forvente at en forbedring i hudplagene nettopp ville inntreffe hos de med mye støv på kontoret, når det elektriske feltet ble redusert. Den multivariate analysen viste betydning av feltreduksjon bare for den delen av materialet, der det var mye støv på kontoret.

I det andre forsøket var endring i støvkonsentrasjon ikke signifikant forklaringsvariabel. Dette kan forklares ved at støvmålingen kun ble utført en enkelt dag for personbårne målinger, og bare over en halv time for stasjonære målinger. Dag-til-dag-variasjonen og ikke minst time-til-time-variasjonen i støvmengden på kontoret viste seg å være svært følsom for aktivitet på kontoret, mens en kan tenke seg at helseeffektmålene reflekterer siste dagers eller siste ukes eksponering.

\section{Regression to the mean}

Det er et kjent statistisk fenomen at biologiske parametre varierer fra et tidspunkt til det neste. Plukker man ut personer med høye verdier av en eller annen parameter ved et tidspunkt, og gjentar målingen etter en tid, vil det vanligvis være slik at verdiene i gjennomsnitt vil ha falt. Dette så vi et eksempel på i inkludering av deltagere i forsøk I hvor deltagerne ble plukket ut etter svar på et spørreskjema utført våren 1996 og forsøket ble gjennomført høsten 1996. I forsøk II ble deltagerne forsøkt fordelt likt i kontrollgruppen og intervensjonsgruppen med hensyn til subjektive irritasjonsplager. Imidlertid viste det seg at fordelingen av nesepassasjemål var skjevfordelt mellom de to gruppene. Målt nesevolum før tiltaket var langt høyere i kontrollgruppen enn $\mathrm{i}$ intervensjonsgruppen og $\mathrm{i}$ den enkle stratifiserte analysen fant vi en stor økning av nesevolumet i intervensjonsgruppen sammenlignet med kontrollgruppen. Multivariat analyse viste at «førverdiene» av nesepassasjen hadde størst innvirkning på endring av nesepassasjemål. Tilsvarende funn ble også gjort på de subjektive symptomer.

Disse funnene understreker hvor viktig det er å ha en kontrollgruppe og at en måler «førverdier» $i$ et intervensjonsforsøk. Det bør også vurderes om man skal sikre at nivået på førverdiene blir likt i intervensjonsog kontrollgruppen.

\section{KONKLUSJON}

Kontrollerte intervensjonsforsøk er en aktuell metode til å evaluere helseeffekter av miljøtiltak. Metoden er relativt ressurskrevende og en støter på en rekke av design- og analyseproblemene som er kjent fra annen epidemiologi. I tillegg er det noen problemer som er mer spesifikke for intervensjonsmetoden, men som er felles med andre eksperimentelle studier som legemiddelfors $ø \mathrm{k}$ (for eksempel kontroll av placebo-effekt, regression to the mean). Metoden vil oftest bare være aktuell for reversible helseeffekter, og helst effekter som endrer seg i løpet av et relativt kort tidsrom. I yrkesepidemiologi er metoden $i$ de senere år benyttet $i$ økende grad innen forskning på helseeffekter i luftveier og muskel-skjelettsystemet. Den er imidlertid også velegnet til å studere relasjonen mellom eksponering og biologiske effekt-markører i andre organsystemer, og er således aktuell for moderne kreft- og reproduksjons-epidemiologi. 


\section{REFERANSER}

1. Cook TD, Campbell DT. Quasi-experimentation. Design and analysis issues for field settings. Boston: Houghton Mifflin Company, 1979.

2. Djupesland P. Å, hvis nesa di er trang, kan du ... akustisk rhinometri- ekkodiagnostikk av nesetetthet. Therapia Medica 1998; 5: 6-9.

3. Fischer EW, Scadding GGK, Lund VJ. The role of acoustic rhinometry in studying the nasal cycle. Rhinology 1993; 31: 57-61.

4. Franke DL, Cole EC, Leese KE, Foarde KK, Berry MA. Cleaning for improved indoor air quality: an initial assessment of effectiveness. Indoor Air 1997; 7: 41-54.

5. Gyntelberg F, Suadicani P, Nielsen JW, Skov P, Valbjørn O, Nielsen PA, Schneider T, Jørgensen O, Wolkoff P, Wilkins CK, Gravesen S, Norn S. Dust and sick building syndrome. Indoor Air 1994; 4: 223-238.

6. Jaakkola JJK, Heinonen OP, Seppänen O. Mechanical ventilation in office buildings and the sick building syndrome. An experimental and epidemiological study. Indoor Air 1991; 1: 111-121.

7. Kemp PC, Dingle P, Neumeister HG. Particulate matter intervention study: A causal factor of building related symptoms in an older building. Indoor Air 1998; 8: 153-171.

8. Kildesø J, Schneider T. Characterization of surface contamination in a cleaning intervention study. Abstract from Indoor Air '96, 1996, vol 4: 151-6, 1996.

9. Martinsen ACT. Statisk personoppladning. Kontinuerlig registrering av personers statiske oppladning gjennom en arbeidsdag. Universitetet i Oslo: Hovedoppgave i fysikk ved Fysisk institutt, 1998.

10. Mayhew T, O'Flynn P. Validation of acoustic rhinometry by using the Cavalieri principle to estimate nasal cavity volume in cadavers. Clin Otolaryngol 1993; 18: 220-225.

11. Miscallef A, Caldwell J, Colls JJ. The influence of human activity on the vertical distribution of airborne particle concentration in a confined environment: Preliminary results. Indoor Air 1998; 8: 131-136.

12. Oftedal G, Vistnes AI, Rygge K. Skin symptoms after the reduction of electric fields from visual display units. Scand J Work Environ Health 1995; 21: 335-344.

13. Raw GJ, Roys MS, Whitehead C. Sick building syndrome: Cleanliness is next to healthiness. Indoor Air 1993; 3: 327-345.

14. Reaves CC. Quantitative research for the behavioral sciences. New York: John Wiley \& Sons, 1992.

15. Skulberg KR, Skyberg K, Eduard W, Goffeng LO, Vistnes AI, Levy F. Inneklima ved dataskjerm - hjelper antistatbehandling av skjermen? Oslo: Statens arbeidsmiljøinstitutt, 1996. HD-1069/96 FOU.

16. Skulberg KR, Skyberg K, Eduard W, Kruse K, Huser PO, Kjuus H, et al. Inneklima på kontoret - hjelper støvsanerende tiltak? Oslo: Statens arbeidsmiljøinstitutt, 1999. HD 1097/98 FOU.

17. Stenberg B. Office illness. The worker, the work and the workplace. Doktoravhandling. Umea Universitet og Arbetsmiljøinstitutet, Solna, 1994. (Omfatter bl.a. artikkelen: A prevalence study of the sick building syndrome (SBS) and facial skin symptoms in office workers. Indoor Air 1993; 3: 71-81.)

18. Wyon D, Andersson B, Söderling M. Fältstudier av åtgärder mot sjuka hus-syndromet - Sammanfattning. Solna: Arbetarskyddstyrelsen, 1992.

19. Wålinder R, Norbäck D, Wieslander G, Smedje G, Erwall C. Nasal mucosal swelling in relation to low air exchange rate in schools. Indoor Air 1997; 7: 198-205.

20. Aarås A, Horgen G, Bjørset H-H, et al. Muskuloskeletal, visual and psychosocial stress in VDU operators before and after multidisciplinary ergonomic interventions. Appl Ergon 1998; 29: 335-354. 